\title{
EL ESTADO DE DERECHO Y LA “SOCIEDAD DE RESTRICCIÓN" EN TIEMPOS DE PANDEMIA
}

\section{THE RULE OF LAW AND THE "RESTRICTION SOCIETY" IN TIMES OF PANDEMIC}

\author{
Markoni Gonzales Pichihua(1) \\ Université Le Havre Normandie, Francia
}

\begin{abstract}
Resumen: La pandemia del coronavirus es el origen de la implementación de regímenes de excepción en varios Estados del mundo. El régimen de excepción forma parte de la estructura de la democracia liberal y es legitimado por el Estado de Derecho. En estos periodos el "monarca republicano" extiende sus poderes y centraliza otros. Se produce una legislación de excepción, se activan las fuentes jurídicas arbitrarias y se desarrolla el Derecho de necesidad. En esta época de excepción, el Estado de Derecho continúa rigiendo, pero pierde efectividad, así como el Estado sigue sujeto al régimen de Derecho, pero comienza a visibilizar sus instituciones arbitrarias. El único contrapeso a la extensión del poder estatal, en estas circunstancias, es el régimen del capital, sobre todo en el ámbito internacional. Este artículo explica la "sociedad de restricción" que se desarrolla en el corazón de los regímenes constitucionales-pluralistas, tanto en periodos ordinarios como de crisis.
\end{abstract}

\begin{abstract}
The coronavirus pandemic is the origin of the implementation of exceptional regimes in several states around the world. The exceptional regime is part of the structure of liberal democracy and is legitimized by the rule of law. In these periods the "republican monarch" extends its powers and centralizes others. Exceptional legislation is produced, arbitrary legal sources are activated and the law of necessity is developed. In this time of exception, the rule of law continues to rule, but loses effectiveness, just as the state is still subject to the rule of law, but begins to make its arbitrary institutions visible. The only counterweight to the extension

(1) Profesor contratado de Derecho Público en la Université Le Havre Normandie (Francia). Doctorando en Derecho Público en el Centro de Investigación LexFEIM de la Facultad de Asuntos Internacionales (Dpto. de Derecho) de la Université Le Havre Normandie. Magíster en Derecho y Ciencia Política por la Université Sorbonne Paris Nord. Abogado por la Universidad Nacional de San Antonio Abad del Cusco (Perú). E-mail: markonigonzales@gmail.com.
\end{abstract}


of state power, in these circumstances, is the regime of capital, especially in the international arena. This article explains the "society of restriction" that develops at the heart of constitutional-pluralist regimes, both in ordinary periods and in crisis.

Palabras Claves: Estado de Derecho, régimen de excepción, régimen capitalista, sociedad de restricción, Covid-19.

Key Words: Rule of law, emergency regime, capitalist regime, restriction society, Covid-19. 


\section{Introducción}

La pandemia por coronavirus (SARS-CoV-2), desde su aparición en diciembre del 2019, produjo (y continúa produciendo) graves consecuencias para la humanidad. Las consecuencias económicas, a mediano y largo plazo, son las más catastróficas en los análisis de los impactos futuros de esta enfermedad ${ }^{(2)}$. Políticamente, hablamos de diversas consecuencias estructurales y reformistas, sobre todo vinculadas a la concentración de poderes y de decisiones políticas, a las limitaciones de las instituciones representativas, a los controles de pueblos enteros, y a la extensión de la "sociedad de restricción". Jurídicamente, las consecuencias son diversas, complejas y técnicas, se ha construido rápidamente un marco legal de excepción para, de una parte, restringir ciertos derechos y libertades, y de otra parte, proteger las vidas de los ciudadanos pero sobre todo para proteger y conservar el régimen del capital, y su categoría fundamental, la propiedad privada. Culturalmente, vemos venir la resurgencia de nacionalismos extremos, la xenofobia, la discriminación y la violencia étnica.

Algunos autores, como Giorgio Agamben (2020), mencionan la inexistencia de una pandemia, afirman que son estrategias de los gobiernos para extender sus tentáculos de dominación, que es exagerado hablar de pandemias, que solo se genera pánico social y caos, etc. Dicen que existen otras enfermedades que causan muchas más muertes al año que el coronavirus, que hay guerras, como en Oriente Medio, que causan miles de muertes por año, y no se hace un escándalo mediático ni se presta la misma atención que al coronavirus.

Pero, de otra parte, la situación de crisis humanitaria que vivimos hoy, a causa de la pandemia, es sui generis, nunca antes se habían visto limitados varios derechos y libertades fundamentales en tantos países a la vez, la concentración de poder, la proliferación de una legislación de excepción, medidas de restricción en diversos sectores productivos, pero sobre todo, la emergencia de un actor poderoso, que recuerda los últimos años tenebrosos del régimen monárquico de la Edad Media, el jefe de Estado.

La producción legislativa extraordinaria se multiplica por todo el mundo y al parecer, al menos por un buen tiempo, la excepción vendrá a ser la regla en el Derecho. En este contexto el Estado de Derecho hace frente a un desafío mayor, positivizar, legitimar y motivar el Derecho de necesidad.

Por estos motivos creemos que es pertinente efectuar un análisis crítico transversal, en esta situación de crisis humanitaria mundial, del debilitamiento del Estado de Derecho, de las legislaciones de excepción, de la concentración de poderes, del desencantamiento de los regímenes constitucionales-pluralistas, de la

(2) Algunas de ellas ya podemos percibirlas, como el ascenso del desempleo, el estancamiento y la perturbación en el proceso de reproducción del capital, inflación económica, caída de los precios del petróleo, los efectos negativos en los mercados de valores en todas partes del mundo, etc. 
dinámica del régimen del capital, y de la extensión de la "sociedad de restricción". Dando respuestas a algunas preguntas, como: ¿es legítimo y legal la creación de regímenes de excepción y la puesta en marcha de una legislación de excepción en un Estado de Derecho? ¿Cuáles son los riesgos políticos y las limitaciones jurídicas en situaciones de excepción? ¿Cuáles son las características del régimen de excepción, y cuáles los posibles controles? ¿De qué manera se muestran las interacciones entre el régimen de excepción y el libre mercado, en circunstancias de excepción? ¿Es que el régimen constitucional-pluralista tiende hacia la "sociedad de restricción"?

Finalmente, un análisis estrictamente jurídico, como el realizado por el profesor español Lorenzo Cotino (2020), no es el más idóneo para abordar un tema como el nuestro. Nuestra metodología es interdisciplinaria, porque tiene en cuenta no solo la esfera jurídica sino también la política, la economía y la sociología, desde una perspectiva del materialismo histórico.

Nuestro trabajo está estructurado en dos partes. En la primera parte, veremos lo concerniente al Estado de Derecho, los regímenes de excepción, la legislación de excepción y la figura del "monarca republicano", en el contexto de la crisis pandémica actual, tanto a nivel interno estatal como a nivel internacional. En la segunda parte, abordaremos las interacciones entre el régimen de excepción, las instituciones políticas y jurídicas estatales y el libre mercado, en este periodo de excepcionalidad, para concluir con la proposición teórica relativa a la "sociedad de restricción" realizada por el autor.

\section{El Estado de Derecho y los regímenes de excepción en tiempos del coronavirus}

Polibio (2010) y Tito Livio (1997), relatan que en la República Romana (509 a. c. - 44 a.c.), en situaciones de grave crisis interna o amenazas foráneas, el Senātus autorizaba a los dos Cónsules designar a un "Dictātŏr" con plenos poderes (imperium), tanto civiles como militares, y legislaba por medio de su propia lex de imperio. Tito Livio iba más allá, afirmaba que el "Dictātŏr" disponía, inclusive, de poderes más importantes que la potestas royale. Durante el periodo excepcional (el mandato del "Dictātŏr" era por máximo, seis meses) el Senātus y las otras magistraturas veían que sus facultades y poderes se restringían, situación perturbadora que, en algunos casos, acababa en graves conflictos políticos.

Desde mucho antes del apogeo romano, el ser humano tiene registros sobre estos periodos de crisis, situaciones de excepción. Dejando de lado las otras causas, la historia nos muestra varios periodos sociales extraordinarios generados por pandemias ${ }^{(3)}$. Hoy, 2020, vivimos un periodo pandémico causado

(3) Contando a partir del siglo XX, hemos tenido una decena de pandemias, entre ellas: la gripe española, el sida, la gripe A (H1N1), el ébola, etc. (Organización Mundial de la Salud, 2019). 
por la enfermedad del coronavirus 2 del síndrome respiratorio agudo grave (SARSCoV-2). Y como en el pasado, las naciones, y sus instituciones políticas, jurídicas y sociales, se preparan para hacerle frente. En nuestros días, en la vanguardia está el Estado, pero no cualquier Estado, sino el Estado de Derecho.

En la actual crisis sanitaria mundial, el rol del Estado se extiende, se profundiza. Vemos que en el marco del Estado de Derecho emerge el régimen de excepción, positivizado y legitimado por el propio Estado. En estos dos últimos meses, hemos visto multiplicarse los regímenes de excepción (llámese estado de emergencia, estado de alarma, estado de emergencia sanitaria, etc.) en todo el mundo. En estas circunstancias de excepcionalidad, el poder político se concentra en la figura de un personaje por demás interesante que Maurice Duverger (1974) denomina "el monarca republicano"(4).

\section{El Estado de Derecho y la "monarquía republicana" frente a la pandemia del coronavirus}

En la teoría del Estado y del Derecho tenemos tres conceptos fundamentales: 1) el régimen constitucional-pluralista ${ }^{(5)}$; 2) las libertades y los derechos fundamentales, y; 3) el Estado de Derecho. Este último, en relación a los otros dos, tiene una prevalencia y una pro-actividad en periodos de excepcionalidad. Además, en estos periodos, como el que vivimos hoy, el tercer concepto condiciona y restringe a los otros dos.

Hablando sobre el Estado de Derecho, podemos afirmar que no hay un consenso teórico en relación a su definición. Pero podemos avanzar con la definición dada por Chevallier (2017):

"En Francia, al igual que en Alemania, el Estado de Derecho es concebido a principios del siglo XX, como un tipo particular de Estado, sujeto a un régimen de derecho: en tal Estado, el poder sólo puede utilizar los medios autorizados por el orden jurídico vigente, mientras que los individuos disponen de recursos judiciales contra los abusos que el Estado pueda cometer ${ }^{\prime \prime 6)}$ (p. 14)

En un Estado de Derecho el gobierno de los hombres (subjetivo, pasional y particular) es reemplazado por el gobierno de las leyes (objetivo, racional y general). Como diría W. Leisner (citado en Chevallier, 2017. p. 61): "el Estado de Derecho no es el gobierno de los hombres, es el reino de las normas".

(4) El "Monarca republicano" es una expresión de Duverger, que lo utiliza para caracterizar los nuevos poderes (amplios, personales, concentrados y superiores) del Jefe de Estado de la Quinta República (1958) en comparación con los de las Repúblicas anteriores.

(5) Al régimen democrático, Raymond Aron (2010) denomina "régime constitutionnel-pluraliste" (traducido al español: "régimen constitucional-pluralista"). Para este autor, este último concepto es mucho más completo que el primero, aunque en sus trabajos a veces utilice estos conceptos como sinónimos.

(6) Todas las traducciones del francés al castellano son del autor del presente artículo. 
Para otros autores, todo Estado es, necesaria y lógicamente, un Estado de Derecho, aquí no interesa si es una monarquía absoluta o una república democrática, un régimen totalitario o un régimen pluralista, al final, todos estos regímenes políticos son "Estados", crean leyes, organizan y centralizan poderes políticos, y mantienen determinadas instituciones jurídicas. Como resalta Hans Kelsen (1945)"Sólo existe un concepto de Estado, el jurídico. El Estado como ordenamiento jurídico centralizado" (p. 242).

De otra parte, hay quienes afirman que el concepto de Estado de Derecho es un concepto vacío, redundante e inútil, porque carece de particularidades y campo de estudio propio en relación al concepto de Estado y al concepto de Derecho. Al respecto Luc Heusching (2002) manifiesta: "el [Estado de Derecho] es vacío, ya que no tiene contenido específico: se limita a remitir, en realidad, al concepto jurídico de Estado. El Estado de Derecho es, por lo tanto, una expresión inútil, porque es pleonástica" (p. 418).

El origen del Estado de Derecho, así como del Estado, lo encontramos en las teorías de la convención social(7), que contrastan con las teorías historicistas ${ }^{\left({ }^{(8)}\right.}$. Por otro lado, el distintivo fundamental de todo Estado es su "poder estatal" que los franceses denominan "soberanía"(9). Es esta "soberanía" que permite al Estado y a los gobernantes: 1) poseer la más grande fuerza existente en la sociedad(10); 2) monopolizar la violencia física y simbólica ${ }^{(11)}$, y; 3) crear una jerarquía de mando/ obediencia y un orden jurídico positivo válido ${ }^{(12)}$.

(7) Las teorías de la convención social son desarrolladas principalmente por John Locke, Jean-Jacques Rousseau y Thomas Hobbes. Por ejemplo, este último nos ilustra: "decimos que un Estado es instituido cuando los hombres en multitud se ponen de acuerdo y resuelven, cada uno con los demás, que, cualquiera que sea el hombre o la asamblea de hombres, a quienes la mayoría ha dado el derecho de representar la persona de todos (es decir, de ser su representante), cada uno, tanto el que votó a favor como el que votó en contra, autorizará todas las acciones y decisiones de este hombre o de esta asamblea de hombres como si fueran suyos propios, con el fin de vivir en paz entre ellos y ser protegidos contra los otros" (Thomas Hobbes, 2004, p. 290, ).

(8) La corriente marxista, con Engels y Marx a la cabeza, es un ejemplo de las teorías histórico-materialistas. De otro lado, está la corriente sociológica, con Weber y Bourdieu, quienes forman parte de las teorías histórico-monopolistas.

(9) El profesor Raymond Carré de Malberg nos ilustra: "Lo que distingue al Estado de todos los demás grupos, es el poder del que está dotado. Este poder, del que sólo él es capaz y que, por lo tanto, lo podemos ya suficientemente caracterizar calificándolo de poder estatal, que lleva, en la terminología tradicionalmente consagrada en Francia, el nombre de soberanía" (Carré de Malberg, 2004, p. 9, ).

(10) Léon Duguit amplía lo dicho, afirmando que: "Los gobernantes poseen, por definición, la más grande fuerza existente en una sociedad determinada; por lo tanto, ellos están obligados, por la regla de derecho, a emplear la más grande fuerza, que ellos disponen, para realizar la solidaridad social. Por lo tanto, ellos deben hacer todas las leyes necesarias para obtener este resultado; y a fortiori ellos no pueden hacer ninguna ley contraria al desarrollo mismo de la solidaridad social" (Duguit, 2007, p. 33, ).

(11) Sobre el particular, Pierre Bourdieu nos dice: "Si tuviera que dar una definición provisional de lo que llamamos "Estado", diría que el sector del poder, que podemos llamar "campo administrativo" o "campo de la función pública", este sector en el que pensamos particularmente cuando hablamos de Estado sin más precisión, se define por la posesión del monopolio de la violencia física y simbólica legítima" (Bourdieu, 2012, p. 14, ).

(12) Hans Kelsen sentencia: "El concepto de « jefe de Estado » implica, por lo tanto, la idea de un orden jurídico válido" (Kelsen, 1945, p. 240, ) 
El Estado, por medio de sus instituciones jurídicas y políticas, actúa en tiempos excepcionales de manera también excepcional. Jurídicamente, durante este periodo, se aplica la legislación de excepcionalidad prevista en el ordenamiento positivo, y, para todo lo no previsto, el Derecho de necesidad ${ }^{(13)}$. Y como diría Mauss (2020): "Es mejor organizar lo excepcional que dejar que lo arbitrario llene el vacío".

En una situación de excepcionalidad se impone un régimen de excepción. En el régimen de excepción, de una parte, la legalidad ordinaria es, relativamente, desplazada por la legalidad excepcional, y de otra parte, se activa el sistema de fuentes del derecho de excepcionalidad. En este contexto, el Estado de Derecho pierde efectividad ${ }^{(14)}$, y varios derechos y libertades son restringidos bajo la vigilancia y el control del parlamento, del órgano judicial y de la prensa ${ }^{(15)}$. Sin embargo, a pesar del control de estas instituciones y contrapoderes, se abre la vía parcial, temporal y discutible de un proceso de desconstitucionalización de ciertos derechos y libertades fundamentales.

En nuestros días, y como consecuencia de la pandemia del coronavirus, muchos Estados han comenzado a implementar regímenes de excepción, como una estrategia para combatirla. Este hecho generó muchas críticas, como la del profesor Dominique Rousseau, quien manifestó su innecesaria creación y su dimensión política, además el riesgo de multiplicar los regímenes de excepción, por lo que llama a no caer en una permanencia de regímenes de excepción ${ }^{(16)}$. Los regímenes de excepción se han multiplicado en el mundo, en todos estos regímenes los roles del jefe de Estado y del jefe de gobierno son preponderantes.

Para definir esta concentración del poder, sobre todo del jefe de Estado, Maurice Duverger (1974) propone la denominación de "monarque républicain"

(13) Sobre el Derecho de necesidad Lorenzo Cotino (2020) nos dice:"En todo caso, la excepcionalidad de natural es escurridiza y no previsible. Por ello, no hay que excluir que ante la falta de previsión en la norma positiva, excepcional y subsidiariamente, haya que acudir al principio de necesidad directamente como principio implícito para resolver situaciones excepcionales. Así, se llega a afirmar que en el caso de que la situación no esté prevista por el Derecho, la necesidad rige como un principio jurídico creativo para adecuarse a la situación".

(14) Según Schmitt:"el Estado de derecho sólo existe si nos encontramos «en una situación normal », pero pierde toda efectividad desde el instante en que nos encontremos « en una situación excepcional ${ }^{\prime \prime}($ citado en Chevallier, 2017, p. 48, ).

(15) Sobre el punto, el profesor Dominique Rousseau nos informa: "Es comprensible que el ejercicio de las libertades sea diferente en tiempos normales y en tiempos excepcionales, pero, como permanecemos en un Estado de derecho, los principios fundamentales deben ser respetados. Lo son, porque el control del Parlamento, del juez y de la prensa está garantizado" (Dominique Rousseau, 2020, ).

(16) El profesor Dominique Rousseau nos dice: Podíamos apoyarnos sobre el carácter extenso de la ley de 1955 modificándola con esta dimensión sanitaria. Esto ya se ha hecho en otras aplicaciones de esta ley. El mensaje es indudablemente político, pero también era necesario proporcionar seguridad jurídica a las decisiones adoptadas hasta este momento. Veo más bien otro riesgo, el de aumentar el número de regímenes de emergencia. Tenemos una de emergencia, de seguridad - la de 1955 -, ahora una de emergencia sanitaria, ¿por qué no mañana una de emergencia medioambiental gracias a la cual el ejecutivo podría imponer nuevas restricciones? Debemos tener cuidado de no multiplicar las situaciones de emergencia, porque existe el riesgo de que el régimen de emergencia se convierta en el régimen normal. Debemos tener cuidado de no deslizarse hacia la permanencia de regímenes excepcionales" (Dominique Rousseau, 2020, ). 
(monarca republicano). Esta expresión nace con la caracterización, que efectúa este autor, sobre los nuevos poderes que dispone el jefe de Estado, en la Quinta República (vigente desde 1958), en relación a las otras Repúblicas del pasado. Los nuevos poderes del presidente de la República son extensos, difusos, superiores (en algunos casos) al legislativo, y personalísimos. Si bien es cierto que en un régimen político presidencialista (o semipresidencialista, como el que tiene Francia) la democracia liberal, las libertades y los derechos fundamentales así como la regla de derecho, son respetados, no se puede negar la preeminencia del poder del ejecutivo, sobre todo del jefe de Estado.

En situaciones de excepcionalidad, como una crisis sanitaria por ejemplo, el actor principal, nuestro monarca republicano, sale a relucir. Y bajo la consigna de la protección de la vida y la seguridad pública, comienza la producción normativa de excepción. Las primeras medidas, como las limitaciones de la libertad de tránsito, la prohibición de salir del domicilio, el cierre de establecimientos, la paralización de centros de producción, la prohibición de reuniones, el control de precios, las requisiciones, hasta el control de comportamientos, hábitos y de la cultura, nos hacen vivir una época de la cual solo teníamos recuerdos y se veía tan lejana.

Lo fascinante de disponer un poder de tales características es la realidad factual de "control" y de "obediencia". Foucault (1975) decía que para tener un control y una vigilancia efectiva es necesario, de una parte, aprender del control y la vigilancia en tiempos de la "peste", y de otra parte, observar detenidamente y tener en cuenta la reproducción de las "instituciones disciplinarias". Pero además del "control", el otro elemento interesante es la "obediencia". Rousseau (2010) afirmaba que si en una colectividad existen opositores minoritarios al mando y a la producción legislativa, ellos serán obligados a obedecer la voluntad general, ellos serán forzados a ser libres. Este último autor afirmaba que la obediencia a la ley es libertad.

China es un ejemplo claro de cómo un régimen de excepción puede acabar en régimen ordinario, es decir que la excepción pasa a ser la regla. Byung-Chul Han (Agamben et al., 2020), en relación al sistema de vigilancia chino, nos informa:

"[En China] Prácticamente no existe la protección de datos. En el vocabulario de los chinos no aparece el término "esfera privada". En China hay 200 millones de cámaras de vigilancia, muchas de ellas provistas de una técnica muy eficiente de reconocimiento facial. Captan incluso los lunares en el rostro. No es posible escapar de la cámara de vigilancia. Estas cámaras dotadas de inteligencia artificial pueden observary evaluar a todo ciudadano en los espacios públicos, en las tiendas, en las calles, en las estaciones y en los aeropuertos" (p. 100).

De otro lado, los países europeos de tradición liberal y cuna de los derechos fundamentales, en épocas críticas, miran hacia aquellos modelos 
de Estado policiaco, queriendo vigilar y controlar a los ciudadanos, así como extender su dominio más allá de lo ordinariamente admitido(17). Estos periodos de excepcionalidad son propicios para la formación de regímenes totalitarios ${ }^{(18)}$.

Para salir de un régimen de excepción, pasada la época crítica, la teoría de la convención social plantea reestablecer la confianza en el pacto social, y esto pasa por el cumplimiento del Estado de Derecho ${ }^{(19)}$. Sin embargo, más que la confianza en el pacto social, es la deslegitimación social del régimen de excepción.

En este contexto crítico por la pandemia, los Estados están decidiendo y actuando rápidamente para salvar a sus ciudadanos, protegiendo sus instituciones políticas y jurídicas, y velando por la economía nacional, han implementado, soberanamente, regímenes de excepción y producido una legislación de excepción, conteniendo relativamente el avance del virus en sus territorios. Sin embargo, el virus no tiene patria, y ya está presente en casi la totalidad de países, en este contexto mundial nos preguntamos, ¿De qué manera cooperan los Estados para abordar el problema del virus? ¿Cuál es el rol de las instituciones internacionales en esta crisis? ¿Existe una organización capaz de liderar el mundo? ¿Cómo queda la sagrada soberanía nacional de los Estados? En las próximas líneas intentaremos contestar estas y otras interrogantes.

\section{El orden internacional en el contexto de la crisis humanitaria}

"Somos olas del mismo mar, hojas del mismo árbol, flores del mismo jardín", es la frase inscrita en las cajas de mascarillas hechas en China que están llegando a Italia. Esta frase nos conduce a pensar en la existencia de una consciencia social mundial, el humanismo antipatriota; de que todos estamos vinculados de manera directa o indirecta; el fenómeno de la globalización, la tecnología y la internacionalización del capitalismo; la cadena de dependencia intergubernamental. Es momento de repensar la soberanía del Estado-Nación.

Antes de la solidaridad entre Estados, lo que existe es la competencia entre Estados. Un ejemplo es la guerra comercial de mascarillas. Ante la necesidad de aprovisionarse de este material, los Estados dejan de lado su espíritu

(17) Como diría Santiago López (Agamben et al., 2020), durante este periodo de excepcionalidad: “El Gobierno se reestataliza y la decisión política regresa a un primer plano. El neoliberalismo se pone descaradamente el vestido del Estado guerra. El capital tiene miedo. La incerteza y la inseguridad impugnan la necesidad del mismo Estado" (p. 58).

(18) Horvat (Agamben et al., 2020) nos dice: "En el libro Black Earth, Timothy Snyder explica que no hay mejor condición para la formación de regímenes totalitarios que las situaciones de emergencia extrema, donde la supervivencia de todos está en juego" (p. 53).

(19) Al respecto Niva Elkin-Koren (2020) nos ilustra: "El restablecimiento de la confianza en un momento de emergencia es esencial para superar las crisis nacionales. Restablecer la confianza en nuestro contrato social requiere el cumplimiento del Estado de derecho. Por lo tanto, asegurar los derechos fundamentales no es un lujo en tiempos de crisis. Es una necesidad para ganar con éxito la lucha contra el virus. Es también una necesidad para asegurar que despertamos en una sociedad libre en el otro extremo de la crisis" (traducción nuestra del inglés). 
cooperativo y miran sus propios intereses nacionales. China deja de lado sus principios comunistas para vender mascarillas al mejor postor. Estados Unidos, nos informa Sami Boukhelifa (2020), consigue mascarillas pagando más (en algunos casos triplicando el precio ofrecido), eliminando la concurrencia fácilmente y requisicionando cargamentos, como hizo con los aviones cargados de mascarillas que estaban destinados para Francia. Vivimos una época, que Boukhelifa (2020) denomina, del "comercio salvaje de mascarillas".

Antes de la cooperación entre Estados, lo que existe es competencia entre Estados. El tema de la vacuna contra el coronavirus es también un buen ejemplo. Varios Estados, sobre todo las potencias mundiales, están en carrera para obtener una vacuna contra la enfermedad del coronavirus, a la cabeza están los Estados Unidos, China, España y Rusia. Pese a la voluntad y esfuerzo de algunos países (como Argentina, Canadá, Francia, Irán, Noruega, Sudáfrica y Suiza) de asociarse y cooperar en esta ardua tarea, el principio de libre concurrencia y maximización de beneficios es la regla. Como diría Daniel López (2020): "[la búsqueda de una vacuna contra el coronavirus] es otra disputa geopolítica: la competencia entre las potencias para ver quién saca primero la vacuna. $Y$ en eso tampoco hay cooperación sino competencia, es decir, 'dialéctica de Estados y de Imperios', que es lo que continuará tras la crisis: y ya veremos con qué fuerza cada potencia".

El Estado de Derecho, desde su perspectiva formal, es ya parte del ordenamiento jurídico mundial. La Organización de las Naciones Unidas, la Organización de Estados Americanos, la Unión Europea, etc., la contemplan y la señalan expresamente. El Estado de Derecho está incorporado en varios instrumentos internacionales, como en la Carta de las Naciones Unidas (1945), la Declaración Universal de Derechos Humanos (1948), el Tratado de la Unión Europea (1993), el Marco del Estado de Derecho europeo (2014). Sin embargo, el principio fáctico de la acumulación de capital internacional, hace que el Estado de Derecho se relativice enormemente, llegando incluso a vaciarlo de contenido y fundamento. El Estado de Derecho, cada vez más, es el lugar del no respeto del Derecho, así como la política es, cada vez más, el lugar del no poder (Horvat en Agamben et al., 2020, p. 44).

Las recomendaciones de algunas organizaciones internacionales, como de la Organización Mundial de la Salud, quedan en eso, en recomendaciones, debido al carácter consultativo no vinculante. Al contrario, las "recomendaciones" de otras instituciones internacionales, como del Banco Mundial (BM) y del Fondo Monetario Internacional (FMI), tienen, fácticamente, un efecto vinculante, sobre todo cuando se trata de reformas fiscales y préstamos gubernamentales. La Directora Gerente del FMI, Kristalina Georgieva, en el contexto de la crisis por el coronavirus, manifestó lo siguiente: 
“EI FMI ofrece aproximadamente USD 50.000 millones a través de servicios financieros de emergencia con rápido desembolso a países de bajo ingreso y de mercados emergentes que podrían solicitar apoyo. De esa suma, USD 10.000 millones están a disposición de los miembros más pobres, libres de intereses, mediante el Servicio de Crédito Rápido" (Fondo Monetario Internacional, 2020)

Estos préstamos, como los tratados de libre comercio, traen letras pequeñas como parte de las cláusulas técnicas del reembolso, "recomendaciones" de políticas económicas, gestión pública y gobernanza, que tienen que cumplir los Estados solicitantes.

Por otro lado, el Estado de Derecho, en el ámbito internacional, está atravesando un periodo de desencantamiento, de poca credibilidad y de deslegitimación social, y que el Estado moderno está fuertemente condicionado por las tendencias del libre mercado. Pero también existen esfuerzos de unión, solidaridad y cooperación entre los Estados. Es un imperativo categórico, hoy más que nunca, realizar la solidaridad y cooperación de todos pueblos. Quizás se inventen nuevas formas de organizar la sociedad global, como la que imagina Slavoj Žižek (Agamben et al., 2020), quien afirma: "probablemente se cree algún tipo de organización global que pueda controlar y regular la economía, así como limitar la soberanía de los Estados Nacionales cuando sea necesario. Los países pudieron hacerlo en el contexto de la guerra en el pasado, y todos nos estamos acercando efectivamente a un estado de guerra médica" (p. 27).

En este contexto internacional de crisis sanitaria y de implantación de regímenes de excepción, observamos la dicotomía entre el patriotismo constitucional y el Estado-Nación. Jürgen Habermas introduce el término de "patriotismo constitucional", que significa defender el régimen democrático constitucional, sin tener en cuenta los límites territoriales de los Estados, defender el régimen democrático constitucional en todos los países, en todo el mundo. Además, el concepto de "patriotismo constitucional" nos incita a pensar internacionalmente, a consolidar el orden jurídico mundial, cuestionando y debilitando los principios del Estado-Nación.

En nuestros días, en plena crisis sanitaria por el coronavirus, quizás las consecuencias políticas y jurídicas no sean tan evidentes y calamitosas como las consecuencias en la esfera económica, sobre todo si miramos el problema mundialmente. La imposición de regímenes de excepción, la producción de una legislación extraordinaria, el debilitamiento del Estado de Derecho, y el desencantamiento de la democracia representativa, no se comparan con los efectos negativos sobre la economía global, sobre todo si miramos las proyecciones a mediano y largo plazo. 


\section{El Estado de Derecho y las imposiciones del mercado en el contexto de crisis pandémica}

En esta parte nos centraremos en dos aspectos. El primero tiene que ver con un análisis del libre mercado y del régimen jurídico-político en el contexto de la crisis sanitaria actual. El segundo abarca el aporte, quizás, más importante del presente trabajo, la "sociedad de restricción".

\subsection{El libre mercado y el régimen jurídico-político en situaciones de excepcionalidad pandémica}

David Harvey (Agamben et al., 2020), en plena crisis sanitaria actual, nos dice:

"Puede que la "gripe española" de 1918 proviniera de Kansas y puede que África incubara el HIV/AIDS, y desde luego inició el virus del Nilo Occidental y el Ébola, mientras que el dengue parece florecer en América Latina. Pero las repercusiones económicas y demográficas de la difusión del virus dependen de grietas y vulnerabilidades en el modelo económico hegemónico" (p. 84).

Efectivamente, las repercusiones del coronavirus, sobre todo en la economía, dependen de los problemas ya existentes, de las limitaciones del propio régimen capitalista en el que vivimos. El capitalismo, o el régimen capitalista, es un sistema económico, político, jurídico, cultural y social, el cual tiene como principio fundamental la valorización del capital ${ }^{(20)}$.

Una característica importante, en la esfera social, es que con la reproducción del régimen capitalista se reproduce también, permanentemente, la relación entre los poseedores de los medios de producción y de vida, y los trabajadores asalariados, o como diría Karl Marx (2008): "El proceso de producción capitalista considerado en su continuidad, o como reproducción, no sólo produce mercancías, ni sólo plusvalía, sino que produce y eterniza la relación social entre capitalista y asalariado" (p. 629).

En esta sociedad capitalista, el poder del Estado se limita no solamente por el Derecho (Estado de Derecho) sino también, y principalmente, por la "perspectiva privada"(21). El proceso histórico de expropiación de la pequeña propiedad campesina, las reivindicaciones de las libertades de industria y comercio, la libre concurrencia, y la elevación de la propiedad privada a derecho fundamental, fueron elementos anteriores a la estructuración del Estado de Derecho.

(20) Karl Marx (2008) afirma: “El poderoso acicate, el gran resorte de la producción capitalista, es la necesidad de valorizar el capital; su objetivo determinante es la mayor extracción posible de plusvalía, o lo que es lo mismo, la mayor explotación posible de la fuerza de trabajo" (p. 418, ).

(21) Según Adrián Rocha (2020): “El Estado debe necesariamente auto-limitarse, pues depende de procesos de producción e intercambio que lo obligan a preservar la perspectiva privada. Sin embargo, para que esa subordinación positiva tenga lugar, debe asimismo desmercantilizar algunas áreas de la vida pública, reorganizar y restringir los mecanismos de acumulación capitalista". 
Este régimen capitalista no conoce de fronteras, de costumbres, de culturas, de religiones, de lenguas, ni de ideologías, allí donde penetra arrasa con todo a su paso. La extensión del capitalismo se traduce en la globalización, la internacionalización de las economías nacionales, el desarrollo del mercado mundial y la interdependencia de los Estados. Pero el inconveniente es que los propios Estados no han avanzado a la misma velocidad ni con la misma intensidad que el capital. Mientras que el capital conquista hasta el último rincón del planeta, los Estados-Nación no logran consolidar una organización política internacional(22), los intentos hechos hasta nuestros días (instituciones transcontinentales, como la Organización de las Naciones Unidas, instituciones regionales, como la Organización de los Estados Americanos, instituciones económicas, como el Espacio Económico Europeo, tribunales internacionales, como la Corte Internacional de Justicia, etc.) muestran sus deficiencias, sus limitaciones y su impotencia pragmática.

En la crisis sanitaria por el coronavirus, como en una crisis bélica ${ }^{(23)}$, el rol del Estado se extiende y profundiza, justamente para defender y conservar el capital ${ }^{(24)}$, sobre todo el capital nacional, y lo hace de tres maneras. Primero, restringiendo ciertas libertades y derechos, como la libertad de tránsito, el derecho a la inviolabilidad del domicilio, la libertad de reunión, el derecho a no ser detenido sin un mandato judicial, etc. Segundo, planificando hasta cierto punto la economía, con la mirada puesta desde arriba por el capital, nacionalizándose ciertos sectores estratégicos económicos (como el sistema de producción y distribución eléctrico, la industria extractiva de hidrocarburos, etc.), impulsando la industria de productos médicos, controlando precios de mercancías estratégicas (trigo, arroz, papa, azúcar, petróleo, gas, etc.), impulsando y financiando a los científicos para crear una vacuna. $\mathrm{Y}$ tercero, creando una reserva militar para garantizar todas las anteriores medidas. Para poner en marcha tremendo plan, los estrechos marcos del régimen del Estado de Derecho son insuficientes, es necesario crear otro régimen, un régimen de excepción, y es justamente lo primero que han decretado los gobiernos de una gran parte de los Estados del mundo.

(22) Al respecto Alain Badiou (Agamben et al., 2020) nos dice: "Aquí llegamos a una contradicción mayor del mundo contemporáneo: la economía, incluido el proceso de producción en masa de objetos manufacturados, es parte del mercado mundial. Sabemos que la simple fabricación de un teléfono móvil moviliza el trabajo y los recursos, incluyendo minerales, al menos en siete Estados diferentes. Pero, por otro lado, los poderes políticos siguen siendo esencialmente nacionales. Y la rivalidad de los imperialismos, antiguos (Europa y Estados Unidos) y nuevos (China, Japón...) prohíbe todo proceso de un Estado capitalista mundial" (p. 73).

(23) Al igual que una crisis sanitaria, la crisis generada por una guerra genera cambios en el régimen político y en el régimen económico, evidentemente en época de guerra estos cambios son mucho más profundos e intensos, como nos informa Badiou (Agamben et al., 2020): "Sabemos desde hace mucho tiempo que, en caso de guerra entre países, el Estado debe imponer, no solamente a las masas populares sino también a los burgueses, restricciones importantes para salvar al capitalismo local. Las industrias son casi nacionalizadas en beneficio de una producción de armamentos desencadenada pero que no produce ningún plusvalor monetario en ese momento. Una gran cantidad de burgueses son movilizados como oficiales y expuestos a la muerte. Los científicos buscan, noche y día, inventar nuevas armas. Un buen número de intelectuales y artistas son requeridos para alimentar la propaganda nacional, etcétera" (p. 74).

(24) Badiou (Agamben et al., 2020) nos dice: "Bajo esta contradicción, los Estados nacionales intentar hacer frente a la situación epidémica respetando al máximo los mecanismos del Capital, aunque la naturaleza del riesgo los obliga a modificar el estilo y los actos del poder" (p. 73). 
El problema de la pandemia viene a complicar la ya estancada economía mundial. Muchos autores afirman que la crisis sanitaria conducirá muy pronto a una crisis económica, sin embargo otros afirman que el capitalismo global ya estaba en problemas y que la pandemia terminaría de sumergirlo en una nueva recesión ${ }^{(25)}$. Los países no terminaron de salir del todo de la crisis del 2008, o dicho de otra manera, después de la crisis del 2008 los Estados no volvieron a ver una etapa de auge o bonanza como la que alcanzaron antes del 2007. A la resaca de la crisis del 2008, se suma una fiesta pandémica que no sabemos cuándo acabará. Por ejemplo Francia, que pensaba crecer este año 1.1\%, verá retroceder su economía, pero no sabemos cuánto, por lo pronto sabemos que en el primer trimestre del 2020 "el producto bruto interno (PBI) francés cayó alrededor del 6\%" (AFP, 2020) y "de acuerdo con las estimaciones del INSEE, el Banco Central Francés estima que cada quincena de confinamiento conlleva una caída del 1,5\% del PIB sobre un año" (AFP, 2020). Finalmente no olvidemos que la deuda del país de Montesquieu es del orden del $112 \%$ del PIB, situación que agrava sus finanzas públicas.

Por otro lado, las contradicciones del régimen del capital, así como sus desigualdades económicas y sociales, hacen posible, en plena crisis sanitaria, explicitar las "discriminaciones de costumbre"(26) mucho más. En este contexto, una parte considerable de la clase asalariada está siendo la más golpeada, por dos razones. Primero, porque está más expuesta al virus que otros sectores sociales, por ejemplo, los trabajadores del sector salud, los de limpieza pública, los del sector transporte, los del sector de logística, etc. Y segundo, porque es más propensa al despido, debido a la crisis económica subsecuente de la pandemia ${ }^{(27)}$.

A su turno, Judith Butler enfatiza: "Es probable que en el próximo año seamos testigos de un escenario doloroso en el que algunas criaturas humanas afirmarán su derecho a vivir a expensas de otros, volviendo a inscribir la distinción espuria entre vidas dolorosas e ingratas" (Agamben et al., 2020, p. 62). Sin embargo, aquel escenario, implícitamente, existe desde mucho tiempo. En nuestros días, un

(25) David Harvey (Agamben et al., 2020) nos ilustra: “El modelo existente de acumulación de capital ya estaba, me parecía a mí, en dificultades. Se estaban sucediendo movimientos de protesta en casi todas partes (de Santiago a Beirut), muchos de los cuales se centraban en el hecho de que el modelo económico dominante no estaba funcionando bien para la mayoría de la población. El modelo neoliberal descansa de manera creciente en capital ficticio y en una ingente expansión de la oferta de dinero y creación de deuda. Se está enfrentando ya al problema de una insuficiente demanda efectiva para realizar los valores que el capital es capaz de producir" (p. 81-82).

(26) Sobre las "discriminaciones de costumbre", Harvey (Agamben et al., 2020) nos dice: "Las repercusiones económicas y sociales se filtran a través de las discriminaciones "de costumbre" que en todas partes quedan en evidencia. Para empezar, la fuerza de trabajo que se espera se ocupe de cuidar a la creciente cifra de enfermos resulta de modo característico enormemente definida en términos de género, raza y etnia en la mayoría del mundo. Es reflejo de la fuerza laboral de clase que se encuentra, por ejemplo, en aeropuertos y otros sectores logísticos" (p. 92).

(27) Al respecto, Harvey (Agamben et al., 2020) afirma:"Esta"nueva clase trabajadora" está en primera fila y lleva la peor parte tanto de ser la fuerza laboral que soporta mayor riesgo del virus en su trabajo o de ser despedida sin recursos, debido al repliegue económico impuesto por el virus. Está, por ejemplo, la cuestión de quién puede trabajar en casa y quién no. Con ello se agudiza la división lo mismo que la cuestión de quién puede permitirse aislarse o ponerse en cuarentena (con o sin salario) en caso de contacto o contagio" (p. 93). 
ejemplo claro es la, todavía, primera potencia del mundo, los Estados Unidos, lugar donde el coronavirus comienza a hacer estragos. Estados Unidos tiene un sistema de salud desigual y excluyente, con $9 \%$ (cerca de 30 millones) de estadounidenses sin ningún tipo de seguro médico (Senserrich, 2020), no existe un sistema universal de salud, y si quieres ser atendido tienes que pagar, el derecho a vivir entre los estadounidenses se reduce a su capacidad financiera (situación que no es diferente en muchos otros países).

Esta crisis pandémica por el coronavirus, en el marco del capitalismo mundial, es una crisis sanitaria de clase, género y raza, como dice Harvey (Agamben et al., 2020): "el avance del COVID-19 exhibe todas las características de una pandemia de clase, género y raza. Si bien los esfuerzos de mitigación se encubren con la retórica de que 'estamos todos juntos en esto', la práctica, sobre todo de los gobiernos nacionales, sugiere motivaciones más siniestras" (p. 93). Observamos, por ejemplo, que en los Estados Unidos, hasta el 8 de abril, "el $62 \%$ de muertos (más de 8 mil muertos) son latinos y afrodescendientes" (El Clarín, 2020).

En fin, vemos que los más afectados con el coronavirus son los asalariados de primera línea que continúan trabajando (como los médicos, los enfermeros, los de limpieza pública, los policías, los asalariados aeroportuarios, los bodegueros, etc.). De otro lado, los grupos más vulnerables son los inmigrantes, como los afrodescendientes y los latinos en Estados Unidos. Como diría Parker Domínguez (citado en Serrano, 2020): "no es una coincidencia que la salud de la población sea un espejo de las inequidades sociales". Ni tampoco es una coincidencia que, desde la aparición y extensión del régimen del capital (siglos XVI-XIX), en cada crisis económica, la clase asalariada sea la más vulnerable, la más afectada, la que pone los muertos, la que se endeuda, y la que paga el salvataje financiero de bancos y grandes empresas.

De otro lado, por primera vez en la historia de los Estados modernos del mundo, una prohibición de salir de casa es decretada en varios países, más de la mitad de la humanidad, es decir más de 3 mil millones de personas (Economía Digital, 2020), no puede transitar libremente, claro está con ciertas excepciones (para comprar alimentos, para trabajar en sectores autorizados, etc.). El problema es que las condiciones materiales, de dicho aislamiento domiciliario obligatorio, varían mucho de país a país, de una nación a otra, de una clase social a otra, de una cultura a otra, e inclusive de un género a otro. No es lo mismo, por ejemplo, que el propietario de Amazon cumpla con dicha medida en su mansión de verano de cuatro hectáreas, con una piscina olímpica, cuatro canchas de tenis y ocho trabajadores domésticos, que el desempleado sin papeles, con cuatro hijos, una esposa enferma, viviendo en un cuartucho alquilado en un suburbio neoyorquino. Entre uno y otro, la diferencia es más que simplemente financiera, 
es una relación social compleja, dos categorías económicas y culturales que pertenecen a diferentes sectores sociales, que se reproducen cada día, cada mes, cada año, que responde a una estructura social desigual, a una sociedad de jerarquías y de honores, a un régimen político de mando, obediencia y dominación, a un régimen jurídico alienante, a un sistema transcultural real y material, a una organización social históricamente determinada, que Marx (2008) denomina "capitalismo".

Si en la época que vivimos, de crisis pandémica por el coronavirus, por un lado, se extiende y profundiza el poder del Estado, motivado y legitimado por el Derecho, y por otro lado, se resalta y agudiza las contradicciones y limitaciones del régimen del capital, es claro que nos dirigimos a la extensión, consolidación y generalización de la "sociedad de restricción".

\subsection{Hacia una "sociedad de restricción"}

Denomino "sociedad de restricción" a una sociedad que tiende hacia lo arbitrario, esto ocurre en los regímenes constitucionales-pluralistas. Sus principales características son: a) el Estado de Derecho ya no es más la cuna de los derechos y libertades fundamentales, ni de la limitación del poder Estatal, estos conceptos se relativizan y tienden hacia una limitación permanente; b) el régimen económico capitalista y su mano invisible siguen vigentes, pero son limitados parcialmente por la expansión gradual del poder del Estado; c) la democracia representativa muestra sus limitaciones, sin embargo, sigue siendo una institución válida, de fundamento y legitimación de la clase gobernante; d) el Estado tiende hacia una complejización y tecnificación, alejándose de los ciudadanos cada vez más; e) la expansión y la tecnificación de la burocracia estatal f) la élite política, económica y científica se reduce cada vez más; g) la sociedad industrial muta hacia una sociedad tecnológica e informatizada, aun bajo los principios de la valorización del capital; $h$ ) el poder de los gobernantes se incrementa y se limitan los dispositivos democrático-participativos; i) el "control" y la "vigilancia tecnificada" del Estado sobre los ciudadanos, se extiende, se generaliza, además, las sanciones se endurecen; j) el único contrapoder, el único que aun restringe el poder del Estado, es el propio capital, sobre todo el capital internacional.

La sociedad de restricción no tiene nada que ver con los regímenes autocráticos ni totalitarios (desarrollados por Raymond Aron y Hannah Arendt), sino que nace y se expande en el corazón mismo de los regímenes constitucionalespluralistas. Tampoco tiene nada que ver con los regímenes históricos despóticos asiáticos ni dictatoriales sudamericanos. La sociedad de restricción es un concepto que se desarrolla "en" y "para" el régimen de la democracia liberal, en el marco del libre mercado. 
La sociedad de restricción se sirve de las teorías de la convención social, que fundan el Estado(28), para racionalizar, legitimar, fundamentar y juridizar ${ }^{(29)}$, la concentración y la monopolización del poder político ${ }^{(30)}$, así comola monopolización de la violencia física ${ }^{(31)}$ y la dominación simbólica ${ }^{(32)}$. La sociedad de restricción nace con el Estado moderno del siglo XVIII, y se desarrolla y extiende en el siglo $X X$. La sociedad de restricción es estructurada y reproducida constantemente por medio de sus instituciones ${ }^{(33)}$ y del habitus ${ }^{(34)}$ de manera consciente $y$, sobre todo, inconsciente, individual y colectivamente.

De otra parte, esta sociedad de restricción es, fácticamente, "restringida" por el libre mercado internacional, y sobre todo por su categoría principal, la propiedad privada ${ }^{(35)}$. El Estado, en cualquier situación, ya sea de paz, de bonanza económica, de guerra, de recesión, de crisis política, etc., está obligado a respetar las leyes invisibles del mercado así como de las categorías básicas del régimen del capital. Paradójicamente, la sociedad de restricción, la sociedad limitante, es restringida a su vez.

(28) Al respecto Hobbes (2004) nos dice: "El Estado es una sola persona o un colegiado, como resultado de acuerdos mutuos de cada miembro de una gran multitud, a fin de que esta persona, o este colegiado, pueda utilizar la fuerza y los medios de todos como considere conveniente para la paz y defensa común" (p. 288-289, ).

(29) Max Weber (1963) afirma que "la autoridad se impone en virtud de la legalidad, en virtud de la creencia en la validez de un estatuto legal y de una competencia positiva fundada sobre reglas establecidas racionalmente".

(30) Como diría Norbert Elias (2003): “La sociedad que llamamos moderna se caracteriza, sobre todo en Europa Occidental, por un cierto nivel de monopolización política" (p. 25, ).

(31) Weber (1963) menciona que el Estado posee la "monopolización de la violencia física legítima", el afirma que "todo Estado sin violencia es la anarquía". A esta definición weberiana del Estado, Bourdieu (2012) añade la violencia simbólica, él manifiesta que el Estado posee la "monopolización de la violencia física y simbólica legítima".

(32) Según Bourdieu (2003): "La dominación, incluso cuando se basa en la fuerza bruta, la de las armas o la del dinero, tiene siempre una dimensión simbólica, y los actos de sumisión, de obediencia, son actos de conocimiento y reconocimiento que, como tales, implementan estructuras cognitivas que pueden aplicarse a todas las cosas del mundo, y en particular a las estructuras sociales. Estas estructuras estructurantes son formas históricamente constituidas, arbitrarias, en el sentido de Saussure y Mauss, cuya génesis social podemos re-trazar" (p. 248, ).

(33) Al respecto Bourdieu (2003) nos ilustra: "El inconsciente es la historia, la historia colectiva que ha producido nuestras categorías de pensamiento, y la historia individual a través de la cual ellas nos han sido inculcadas: por ejemplo, la historia social de las instituciones educativas (banal entre todas, y ausente de la historia de las ideas, filosofías u otras) y la historia (olvidada o reprimida) de nuestra relación singular con estas instituciones que podemos esperar algunas verdaderas revelaciones sobre las estructuras objetivas y subjetivas (clasificaciones, jerarquías, problemáticas, etc.) que guían siempre, a pesar de nosotros mismos, nuestro pensamiento" (p. 23,).

(34) Sobre el habitus el profesor Bourdieu (2003) nos dice: Contra una [el mecanismo] y la otra teoría [el finalismo], debemos plantear que los agentes sociales están dotados de habitus, inscritos en los cuerpos por las experiencias pasadas: estos sistemas de formas de percepción, de apreciación y de acción permiten realizar actos de conocimiento práctico, basados en la identificación y el reconocimiento de los estímulos condicionales y convencionales a los que están dispuestos a reaccionar, y generar, sin posición explícita de fines ni cálculo racional de medios, estrategias adaptadas y constantemente renovadas, pero dentro de los límites de las restricciones estructurales de las que son producto y que los definen" (p. 200-201,).

(35) Sobre la importancia de la propiedad privada en el Estado, Marx (1975) nos dice: "si la "propiedad privada independiente", en el Estado político, tiene el significado de la Independencia política, esa propiedad privada es la independencia política del Estado. La "propiedad privada independiente" o la "propiedad privada real" es entonces no sólo "el soporte de la Constitución" sino la "Constitución misma" (p. 168, ). 
En la sociedad de restricción las diferencias entre la clase dominante y las clases dominadas, se evidencian y se exteriorizan por medio de la "hegemonía cultural"(36), y se garantizan por medio de la "fabricación del consentimiento"(37). Además, en el terreno económico, la clase capitalista domina no solamente por la fuerza sino también por el consentimiento (cubierto de coerción), por medio de esta misma hegemonía cultural. Aquí la dominación no es pura violencia (Weber, 1963) ni pura dominación cultural (Bourdieu, 2003), sino la articulación de estas dos.

En todos los estudios sociales existen limitaciones, excepciones o cuestionamientos a los planteamientos teóricos. Veamos algunas limitaciones de nuestro concepto de "sociedad de restricción". Podemos adelantar tres limitaciones: a) si bien es cierto que la democracia representativa liberal es, aun, el fundamento y la legitimación de la clase gobernante, existe un movimiento internacional, tanto en la academia como en la práctica social, a favor de la democracia participativa y deliberativa ciudadana, que contrarresta relativamente la sociedad de restricción; b) si bien las tecnologías de la información y comunicación son creadas y controladas por unas élites, tratando de imponer un discurso ideológico dominante, el uso masivo, el uso popular, tiende a criticar esta manipulación, a denunciar la arbitrariedad, la corrupción, la limitación de libertades y derechos, creando un discurso contra-elitista, contra-hegemónico, oponiéndose a las élites políticas y económicas, y; c) finalmente, la crítica más importante viene de la propia práctica social, de los movimientos sociales reivindicativos, como el de los asalariados, de los indígenas, de los campesinos, de los estudiantes, de los ecologistas, etc., que se oponen a la sociedad de restricción.

Estas limitaciones relativizan el concepto de "sociedad de restricción", sin embargo, podemos afirmar que la tendencia general, en la mayoría de los Estados del mundo, es que se extienda y se consolide. Todo el sistema político liberal, así como el régimen capitalista y la estructura cultural alienante, con sus instituciones, normas y costumbres, están orientados al triunfo de la "sociedad de restricción".

En épocas de crisis sociales, como la crisis pandémica por la enfermedad del coronavirus, la sociedad de restricción se percibe y visibiliza más que en épocas de no crisis. Un ejemplo es la puesta en marcha del régimen de excepción

(36) La teoría de la "hegemonía cultural" es desarrollada por Antonio Gramsci (1990). Este autor menciona que el tema de la hegemonía está presente en todo análisis político, económico, filosófico y cultural. La hegemonía cultural está ligada a la forma como una clase social llega a ejercer su dominación sobre las otras, a su conservación y reproducción, teniendo en cuenta todas las formas que ella toma y todos los instrumentos que utiliza.

(37) La "fabricación del consentimiento" es un concepto de Noam Chomsky et Edward Herman (2008), quienes afirman que los medios de comunicación masivos difunden, principalmente, el pensamiento de la clase dominante, manteniendo, de esta manera, el orden establecido. Las élites controlan y manipulan la información a favor de sus intereses, es un proceso de adoctrinamiento de la población, por medio de la posesión y concentración de los medios de comunicación en un grupo de propietarios cada vez más reducido. 
(limitación relativa de la libertad de tránsito, suspensión relativa de ciertos derechos, producción legislativa por medio de decretos presidenciales, expansión e intensificación del poder de las fuerzas armadas, etc.). No debemos confundir el régimen de excepción con la "sociedad de restricción". El régimen de excepción es un elemento de la sociedad de restricción en periodo de excepcionalidad. La sociedad de restricción abarca los regímenes constitucionales-pluralistas (repúblicas y monarquías constitucionales), en el marco del régimen económico capitalista, tanto en periodos ordinarios como en periodos de excepcionalidad.

Contrariamente al discurso profano, de una parte, la sociedad de restricción modifica, reestructura y adapta el Estado de Derecho, y de otra parte, el Estado de Derecho "legitima" y "legaliza" la sociedad de restricción. Los regímenes constitucionales-pluralistas tienden a ser más compatibles y receptivos con la presencia y expansión de la sociedad de restricción.

En nuestros días, existe un peligro potencial y real en los sistemas democráticos liberales, relacionado al proceso de "regularización" y de "regulación" de las estructuras de prácticas y de representaciones de la sociedad de restricción, sin la intervención, siquiera, de la fuerza pública. Es, a mi parecer, el nuevo habitus de la sociedad de restricción ${ }^{(38)}$, que veremos generalizarse dentro de no mucho tiempo. Estamos viviendo una mutación en las costumbres, un proceso de transformación social, a la vez nacional e internacional, donde se está creando una nueva costumbre, una nueva arbitrariedad histórica, que sustenta y legitima la sociedad de restricción.

A nivel internacional, la sociedad de restricción se está "naturalizando", gradual y progresivamente, por medio de las propias instituciones históricas del Estado ${ }^{(39)}$. Además, en nuestros días, las prácticas y representaciones colectivas de la sociedad de restricción difieren enormemente de un Estado al otro. Por ejemplo, en varios Estados asiáticos la sociedad de restricción está ganando terreno a pasos agigantados, varios Estados asiáticos ya han naturalizado ciertas

(38) Al respecto Bourdieu (2000) nos dice: "Las estructuras que son constitutivas de un tipo particular de ambiente (por ejemplo, condiciones materiales de existencia características de una condición de clase) y que pueden ser capturadas empíricamente en forma de regularidades asociadas a un entorno socialmente estructurado producen habitus, sistemas de disposiciones duraderas, estructuras estructuradas predispuestas a funcionar como estructuras estructurantes, es decir, como principio de generación y de estructuración de prácticas y de representaciones que pueden ser objetivamente "reguladas" y "regulares" sin ser en modo alguno producto de la obediencia a normas, objetivamente adaptadas a su finalidad sin suponer el objetivo consciente de los fines y el dominio expreso de las operaciones necesarias para alcanzarlos y, siendo, todo ello, colectivamente orquestado sin ser el producto de la acción organizadora de un director de orquesta" (p. 256, ).

(39) Sobre este punto, Bourdieu (2003) nos explica: "al origen, sólo existe la costumbre, es decir, la arbitrariedad histórica de la institución histórica, que se hace olvidar como tal, basándose en la razón mítica, con las teorías del contrato, verdaderos mitos de origen de las religiones democráticas (que recientemente han recibido su brillo de racionalidad con la teoría de la justicia de John Rawls), o, más banalmente, naturalizándose, y obteniendo así un reconocimiento enraizado en la ignorancia" (p. 137, ). 
categorías e instituciones de la sociedad de restricción, bajo denominaciones como "instituciones de seguridad nacional", o "legislaciones de seguridad ciudadana", controlando y vigilando a los ciudadanos en unas dimensiones hasta hace poco inimaginables. De otro lado, en los Estados Europeos, la sociedad de restricción comienza a aparecer mediante instituciones y leyes "antiterroristas", haciendo, por ejemplo, de los controles e investigaciones policiales excepcionales, una regla. Y si en tiempos ordinarios, los europeos se asombraban y criticaban el régimen policiaco de los Estados asiáticos, sobre todo de China, hoy, en tiempos de crisis, ven en ciertas instituciones asiáticas una "estrategia" a seguir parcialmente.

Por otro lado, el Estado que hable más de libertad, de respeto de los derechos humanos, y de dignidad humana, será el Estado que más se aproxime a la "sociedad de restricción". La retórica estatal históricamente ha contrastado con la práctica estatal, el análisis de la democracia y el poder invisible de Bobbio (2009) es un buen ejemplo. En la sociedad de restricción no es recurrente utilizar la fuerza física, ni mucho menos obtener una obediencia forzada, basta estructurar y naturalizar ciertas conductas sociales y exhibir el dominio de la fuerza, sobre todo de la fuerza en potencia ${ }^{(40)}$. Las representaciones de dominio, los signos de mando y los símbolos de arbitrariedad dominan el campo de acción de la sociedad de restricción.

En la sociedad de restricción se desarrolla un proceso constante de concentración, de centralización y de monopolización de la información, acometido por una élite económica reducida y por el Estado. En el siglo XXI la información, como el conocimiento científico, es poder, aquellos que controlen la información controlarán relativamente la estructura social-cultural, ordenándola, controlándola y manipulándola a favor de determinados intereses. Además, está claro que la información, en nuestros días, es una mercancía, que puede comprarse y venderse sin ningún inconveniente. Este proceso de concentración, monopolización y centralización de la información es legitimado individualmente, pero sobre todo colectivamente, conscientemente, pero sobre todo inconscientemente, por medio de la construcción permanente de nuevos habitus.

Las tecnologías de la información y de la comunicación vienen a facilitar la extensión de la sociedad de restricción. Proyectos como el Big Data, el XKeyscore, el Bullrun y el Optic Nerve tienen la finalidad de colectar, almacenar, analizar, catalogar, vigilar y ofertar la información relativa a las conductas de los individuos,

(40) Sobre el particular, Bourdieu (2003) nos ilustra: "la exhibición de fuerza, en la parada militar, pero también en la ceremonia judicial - como analiza E. P. Thompson - implica, en efecto, una exhibición del dominio de la fuerza, así mantenida en el estatus de fuerza en potencia, que podría ser utilizada pero que no se utiliza: mostrarla, es mostrar que es lo suficientemente fuerte, y lo suficientemente segura de sus efectos, para evitar la necesidad de actuar". (p. 138-139). 
haciendo posible un control conductual social y haciendo previsible las relaciones intersubjetivas. Pese a la denuncia de la existencia activa de estos programas de vigilancia masiva, como el realizado por Edward Snowden (a partir del 2013), estos programas, y otros, continúan desarrollándose, a iniciativa privada y bajo el soporte del Estado.

La monopolización de la información, en la esfera estatal, conduce esencialmente al control/mando y a la vigilancia/obediencia de las personas. En la sociedad de restricción, la monopolización de la información es un presupuesto básico. Una vez que el Estado obtiene esta información, de sus instituciones propias o del sector privado, conoce las particularidades de un individuo, su localización, las personas de su entorno, sus actividades personales y laborales, su manera de pensar, sus preferencias comerciales, etc. Es posible que en un futuro próximo, el Estado pueda controlar el pensamiento de las personas, inclusive sus características biológicas ${ }^{(41)}$.

De otro lado, la monopolización de la información, en la esfera privada, sirve fundamentalmente a los fines de la acumulación del capital. Un ejemplo es la gestión del Big Data, los datos de los ciudadanos, permiten conocer los comportamientos económicos, información relacionada al consumo, las transacciones bancarias, preferencias, etc., para influir en las decisiones económicas, crear necesidades, mercados artificiales y multiplicar el consumo. El control de los comportamientos económicos individuales y colectivos se inscribe perfectamente dentro de los parámetros de la sociedad de restricción. A nivel internacional, la monopolización de la información es una herramienta primordial para acceder y controlar el mercado mundial. En este contexto es difícil escapar a una vigilancia comportamental económica, así como es complicado hacerle frente a las influencias y presiones de las élites económicas a consumir determinadas mercancías.

El Estado en la sociedad de restricción no posee solamente el monopolio de la violencia física y simbólica legítima, sino también el monopolio de la información. En periodos de excepción, con la implementación de regímenes de excepción, es fundamental que el Estado tenga el control de la información, para ello es necesario que trabaje con las grandes empresas del sector de las tecnologías de la información y de la comunicación, y si fuera necesario intervenirlas por medio de la fuerza.

(41) Sobre este tema, Byung-Chul Han nos dice: "Los proveedores chinos de telefonía móvil y de Internet comparten los datos sensibles de sus clientes con los servicios de seguridad y con los ministerios de salud. El Estado sabe por tanto dónde estoy, con quién me encuentro, qué hago, qué busco, en qué pienso, qué como, qué compro, adónde me dirijo. Es posible que en el futuro el Estado controle también la temperatura corporal, el peso, el nivel de azúcar en la sangre, etc. Una biopolítica digital que acompaña a la psicopolítica digital que controla activamente a las personas" (p. 102). 
Finalmente, la expansión y consolidación de la sociedad de restricción no es un presagio, no es un asunto fatalista, por el contrario, la sociedad de restricción es una tendencia histórica, una tendencia en los Estados modernos constitucionales-pluralistas. Tendencia que no es lineal ni mecánica, que puede ser acelerada o retrasada, incluso revertida, según sea el caso y en función de determinadas condiciones. En nuestros días podemos ver ya varios elementos y características de la sociedad de restricción, en varios Estados del mundo, cada uno con sus particularidades, y con una extensión desigual. Y si los gobiernos de los Estados declaran la necesidad de la restricción y de la arbitrariedad por temas de seguridad nacional, defensa de derechos fundamentales, libertad y paz, en la práctica lo hacen casi siempre por lo contrario.

\section{Conclusión}

Como hemos visto, la decisión gubernamental de instaurar un régimen de excepción como estrategia contra la propagación del coronavirus tiene un significado mayor que la implementación excepcional de una serie de medidas limitativas de libertades y derechos, de prohibiciones y mandos, de reformas financieras y sociales. Además, teniendo en cuenta que el régimen de excepción es un elemento de la "sociedad de restricción" en periodos extraordinarios, éste forma parte del régimen constitucional-pluralista y del Estado de Derecho. Finalmente, el único límite fáctico al poder del Estado, en este periodo de excepcionalidad, es el capital, sobre todo el capital internacional, los otros límites jurídicos y contrapesos políticos se relativizan y neutralizan.

Y una vez más, los hechos y la práctica social nos dan lecciones, o como diría Slavoj Žižek (Agamben, et al., 2020) "El punto es reflexionar sobre un hecho triste de que necesitamos una catástrofe para que podamos repensar las características básicas de la sociedad en la que nos encontramos" (p. 24). Repensar, también, en una sociedad diferente a la "sociedad de restricción", que viene ganando terreno, tanto en periodos ordinarios como en periodos de crisis, en la mayoría de los Estados del mundo. 


\section{Bibliografía}

AGAMBEN, G., Žižek, S., Butler, J., Badiou, A., Harvey, D., et al., (2020). Sopa Wuhan. Pensamiento contemporáneo en tiempos de pandemia. España: Editorial Aspo.

ARON, R. (2010). Démocratie et Totalitarisme. Paris : Éditions Gallimard.

BOBBIO, N. (2009). Estado, gobierno y sociedad. Por una teoría general de la política. México: Fondo de Cultura Económica.

BOURDIEU, P. (2000). Esquisse d'une théorie de la pratique. Précédé de Trois études d'ethnologie kabyle. France : Éditions du Seuil.

BOURDIEU, P. (2003). Méditations pascaliennes. France : Éditions du Seuil.

BOURDIEU, P. (2012). Sur l'État. Cours au Collège de France (1989 - 1992). France : Éditions Raisons d'agir/Éditions du Seuil.

CARRE DE MALBERG, R. (2004). Contribution à la théorie générale de l'État. Paris : Éditions Dalloz.

CHEVALLIER, J. (2017). L'État de droit. Issy-les-Moulineaux : Extenso éditions.

CHOMSKY, N. et HERMAN, E. (2008). La fabrication du consentement. Delapropagande médiatique en démocratie. France : Éditions Agone.

COTINO HUESO, L. (2020, marzo-abril). Los derechos fundamentales en tiempos del coronavirus. Régimen general y garantías y especial atención a las restricciones de excepcionalidad ordinaria. Revista El Cronista del Estado Social y Democrático de Derecho, Núm. 86-87. España.

DUGUIT, L. (2007). Manuel de droit constitutionnel. Paris : Éditions Panthéon-Assas.

DUVERGER, M. (1974). La monarchie républicaine ou comment les démocraties se donnent des Rois. Paris : Edition Robert Laffont.

ELIAS, N. (2003). La Dynamique de l'Occident. Paris : Éditions Calmann-Lévy.

FOUCAULT, M. (1975). Surveiller et punir. Naissance de la prison. Paris : Gallimard.

GRAMSCI, A. (1990). Cahiers de prison (tome IV). Paris : Éditions Gallimard.

HEUSCHING, L. (2002). État de droit, Rechtsstaat, Rule of law. Paris : Éditions Dalloz.

HOBBES, T. (2004). Léviathan. Paris : Éditions Gallimard. 
KELSEN, H. (1945). Théorie générale du droit et de l'Etat. Paris : Bruylant.

MARX, K. (1975). Critique du droit politique hégélien (traduction de Baraquin A.). Paris : Éditions Sociales.

MARX, K. (2008). Le capital, livre premier : développement de la production capitaliste (éditions établie et annotée par Maximilien Ruben). Paris : Éditions Gallimard.

POLYBIUS. (2010). The Histories. Great Britain: Oxford University Press.

ROUSSEAU, D. (2020, mars). Attention à ne pas multiplier les états d'urgence. Le Point. https://www.lepoint.fr/societe/dominique-rousseau-attention-a-ne-pasmultiplier-les-etats-d-urgence-20-03-2020-2368064_23.php

ROUSSEAU, J.J. (2010). Du contrat social ou Principes du droit politique. Paris : Éditions Honoré Champion.

TITO LIVIO. (1997). Historia de Roma. Desde la fundación de la ciudad (vol. I). Madrid: Edición Antonio Fontán.

WEBER, Max. (1963). Le savant et le politique. Paris : Éditions Plon. 